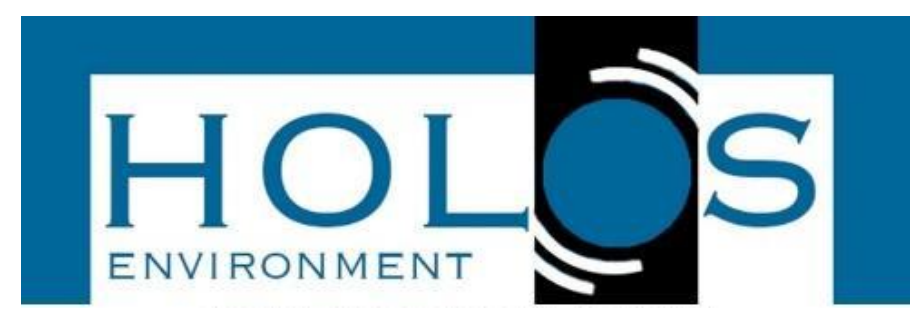

\title{
BALANÇO DAS AÇÕES RELATIVAS À GESTÃO DE RECURSOS HÍDRICOS PROPOSTAS NO PLANO HIDROAMBIENTAL DA BACIA DO CAPIBARIBE (PE)
}

\section{BALANCE OF ACTIONS RELATED TO THE MANAGEMENT OF WATER RESOURCES PROPOSED IN THE HYDROENVIRONMENTAL PLAN OF THE CAPIBARIBE BASIN}

(PE)

\author{
Nílberte Muniz Sousa1; Elivelthon Carlos Nascimento²; Maria Fernanda de Almeida \\ Portela $^{3}$; Amanda Almeida de Oliveira Figueiredo ${ }^{3}$
}

Artigo recebido em: 16/05/2020 e aceito para publicação em: 25/08/2020.

DOI: http:/dx.doi.org/10.14295/holos.v20i4.12397

\begin{abstract}
Resumo: O presente estudo tem como objetivo o levantamento do andamento das ações relativas à gestão de recursos hídricos propostas no Plano Hidroambiental da bacia hidrográfica do Rio Capibaribe, localizada na porção nordeste do Estado de Pernambuco. A metodologia ocorreu a partir das seguintes etapas: análise da documentação disponível para a comunidade, reuniões para obter informações mais restritas com membros do comitê e funcionários de órgãos públicos, elaboração de gráficos e análise crítica do planejamento e execução. Os resultados mostraram que a partir das ações planejadas $23 \%$ não foram iniciadas, $31 \%$ foi iniciado, $23 \%$ foi concluída e $23 \%$ as intuições responsáveis não souberam informar. Apesar do planejamento a implantação prática encontrou diversas dificuldades, sendo um dos maiores desafios na implantação da gestão a definição dos responsáveis por cada atividade, o acompanhamento das ações e a integração entre diferentes instituições públicas. Portanto, a elaboração de um documento para gestão dos recursos hídricos em uma bacia hidrográfica, não garante o cumprimento das ações nos prazos estabelecidos. Assim, no plano da bacia é primordial identificar e informar os responsáveis por cada uma das ações estabelecidas e criar uma plataforma integradas para que diferentes instituições possam informar 0 andamento das ações.
\end{abstract}

Palavras-chave: Rio Capibaribe. Gestão Hídrica. Comitê da bacia.

\begin{abstract}
The present study aims to survey the progress of actions related to the management of water resources proposed in the Hydro-Environmental Plan of the hydrographic basin of the Capibaribe River, located in the Northeastern portion of the State of Pernambuco. The methodology considered the following steps: analysis of the documentation available to the community, meetings to obtain more restricted information with members of the committee and employees of public agencies, preparation of graphics, and critical analysis of the planning and execution. The results showed that from the planned actions $23 \%$ were not initiated, $31 \%$ was initiated, $23 \%$ was completed and $23 \%$ the responsible intuitions did not know how to inform. Despite the planning, practical implementation encountered several difficulties, one of the biggest management challenges being the definition of those responsible for each activity, the monitoring of actions, and the integration between different public institutions. Therefore, the elaboration of a document for the management of water resources in a hydrographic basin does not guarantee compliance with the actions within the established deadlines. Thus, in the management document of the hydrographic basin plan, it is essential to identify and inform those responsible for each of the established actions and to create an integrated platform so that different institutions can inform the progress of the actions.
\end{abstract}

Keywords: Capibaribe River. Water Management. Basin committee.

\footnotetext{
${ }^{1}$ Instituto Federal da Paraíba (IFPB), João Pessoa, PB. E-mail: nilberte.muniz@hotmail.com

${ }^{2}$ Instituto Federal do Sertão Pernambucano (IF Sertão PE), Petrolina, PE. E-mail: elivelthonnascimento@gmail.com

${ }^{3}$ Escola Politécnica do Pernambuco (POLI/UPE), Recife, PE. E-mails: fernandaportela40@gmail.com, amandaalmeida1602@gmail.com
} 


\section{INTRODUÇÃO}

A água é um recurso fundamental para a manutenção da população e desenvolvimento das cidades, mas, com o aumento populacional e expansão da industrialização, vários países do mundo vêm enfrentando uma grave crise dos recursos hídricos (FIGUEIREDO, 2019). Dessa forma, os usos múltiplos e competitivos da água se acentuam e colocam pressões adicionais sobre quantidade e qualidade da água (TUNDISI, 2013).

Na gestão dos recursos hídricos, a insuficiência de planejamento, em conjunto com a falta de racionalidade e de conservação, ocasionou um aumento na escassez hídrica, originada pelo desperdício e pela degradação (GOUVEIA; PEDROSA, 2015). Além disso, a situação crítica dos recursos hídricos é acentuada pela crise de governança, com falhas de gestão das instituições responsáveis pelo gerenciamento dos nossos recursos naturais, afetando o bem-estar humano e ecossistêmico (MESQUITA, 2017).

À medida que a economia se desenvolve e se diversifica, maior é a necessidade de uma gestão eficiente e participativa, cooperando para o gerenciamento do estresse hídrico, regulando a demanda e compartilhando os usos múltiplos (TUNDISI, 2013). Nesse sentido, cresce a importância do planejamento ambiental e da gestão dentro das bacias hidrográficas para manter a preservação, planejar a recuperação de áreas degradadas e gerir a utilização adequada dos recursos hídricos.

Dessa forma, o diagnóstico da bacia hidrográfica é de fundamental importância para que se tenha um planejamento adequado às inúmeras atividades desempenhadas na região (COSTA et al., 2015). Assim, a gestão das bacias deve permitir uma visão realista, levando-se em consideração as condições naturais, o uso do solo e as atividades humanas nelas desenvolvidas (LIMA et al., 2018).

A Política Nacional de Recursos Hídricos (PNRH), criou o Sistema Nacional de Gerenciamento de Recursos Hídricos (SINGREH) (BRASIL, 1997), necessário para viabilizar o entendimento das dinâmicas dos processos de tomada de decisões na gestão hídrica nacional e, primordialmente, estaduais (THEODORO; NASCIMENTO; HELLER, 2016). Esta lei ficou conhecida como a "Lei das Águas" do Brasil, possibilitando aos recursos hídricos uma maior prioridade nas políticas públicas nacionais. Ademais, essa lei consistiu um passo fundamental em direção à democracia e desenvolvimento da cidadania, uma vez que incorporou a participação social na gestão destes recursos (BARBOSA; LOPES; CARPI JUNIOR, 2015). 
As bacias hidrográficas são as unidades territoriais para implantar a PNRH (BRASIL, 1997), cujos órgãos consultivos e deliberativos de gerenciamento são denominados Comitês de Bacias Hidrográficas (COBH). O COBH se constitui como espaço político de integração entre os setores usuários, a população e o poder público no processo de tomada de decisões no âmbito da gestão das águas (DULAC e CRUZ, 2015). Entre as suas principais funções está a de promover o debate das questões relacionadas aos recursos hídricos da bacia através de reuniões do comitê, que posteriormente apresentam as decisões à comunidade. Portanto, é essencial que nos COBHs discutam-se as necessidades de garantia de princípios como a disponibilidade da água para a atual e futuras gerações, visando a disponibilização, em quantidade e qualidade adequadas para o seu consumo, bem como proporcionar o uso múltiplo das águas (LIMA et al., 2018; RHODEN et al., 2016).

No contexto da gestão dos recursos hídricos, esses diálogos são a base para a formulação dos Planos de Bacias Hidrograficas, onde serão dadas as diretrizes para o seu planejamento e o processo de gestão das águas. (BARBOSA; LOPES; CARPI JUNIOR, 2015).

Os planos de bacias são fundamentais para a previsão e o gerenciamento das demandas futuras, sendo estas fortemente influenciadas, segundo Ribeiro Neto et al. (2014), não apenas pelas tendências demográficas, mas também pela alocação de água aos diferentes usos, eficiência, preços, fornecimento, racionamento, regimes e conscientização do usuário final.

A bacia hidrográfica do Rio Capibaribe engloba as regiões Agreste, Zona da mata e litoral do Estado de Pernambuco. Segundo Andrade (2007), juntamente com os Rios Una e Ipojuca, o Capibaribe compõe o grupo dos três rios mais importantes do Estado. Por onde passa, esse rio assume o papel de manancial principal, responsável pelo abastecimento público da bacia, com destaque para sua parte perene, onde se localiza a Região Metropolitana do Recife (SALGUEIRO et al., 2014). O Rio Capibaribe abastece 43 municípios representando 43\% da população pernambucana (SILVA et al., 2016).

Nesse sentido, o Plano Hidroambiental da Bacia Hidrográfica do Rio Capibaribe (PHA Capibaribe) foi aprovado pelo COBH Capibaribe em 2010 onde estabeleceu planos de investimentos como ações complementares àquelas já implantadas, em implantação ou planejadas para a Bacia Hidrográfica do Rio Capibaribe (BHRC) em três eixos temáticos: socioambiental, infraestrutura hídrica e gestão dos recursos hídricos. 
A vinculação entre a gestão hídrica e as políticas públicas é um movimento que deve ser mais estudado e praticado, principalmente na direção de uma perspectiva de incorporação da gestão pública (THEODORO; NASCIMENTO; HELLER, 2016). Diante disto, o objetivo desta pesquisa se constitui de uma análise das ações relativas à gestão de recursos hídricos executada pelos órgãos públicos competentes, comparando-se com as ações propostas no PHA Capibaribe.

\section{BACIA DO RIO CAPIBARIBE}

A BHRC, localizada na porção nordeste do estado, possui uma área de $7.454,88$ $\mathrm{km}^{2}$, equivalente a $7,58 \%$ do território de Pernambuco (Figura 1). Corresponde à unidade de planejamento hídrico UP2, e abrange parte das Regiões de Desenvolvimento (RD) do Agreste Central, Agreste Setentrional, Mata Sul, Mata Norte e Região Metropolitana (PERNAMBUCO, 2010).

Segundo Löbler et al. (2016) a bacia do Capibaribe apresenta uma abrangência regional (agreste, mata e litoral) que confere à BHRC um ambiente complexo no qual se evidenciam contrastes climáticos, de relevo, de solos e de cobertura vegetal, além de socioeconômicos, que exigem um modelo de gestão hídrico e ambiental, que atenda às suas peculiaridades sub-regionais e locais.

Sua rede hídrica tem como constituintes principais, pela margem direita, o riacho Aldeia Velha, riacho Tabocas, riacho Carapotós, rio Cachoeira, riacho das Éguas, riacho Cassatuba, riacho Grota do Fernando, rio Cotunguba, riacho Goitá, rio Tapacurá e muitos outros de menor porte. Pela margem esquerda, tem-se o riacho Jundiá, riacho do Pará, riacho Tapera, riacho do Arroz, riacho da Topada, riacho Caiaí, rio Camaragibe ou Bezouro, além de um grande número de rios e riachos de pequeno porte (Figura 2) (PERNAMBUCO, 2010).

Os principais reservatórios são: Jucazinho, Carpina, Tapacurá, Goitá, Poço Fundo. Além desses, vale a pena citar outros reservatórios tais como: Engenho Gercino de Pontes, Várzea do Una, Oitís, Santa Luzia, Matriz da Luz, Machado e Lagoa do Porco. 
Figura 1 - Localização da Bacia Hidrográfica do Rio Capibaribe



Fonte: Silva et. al. (2016)

Figura 2 - Bacia hidrográfica do Rio Capibaribe e seus principais afluentes

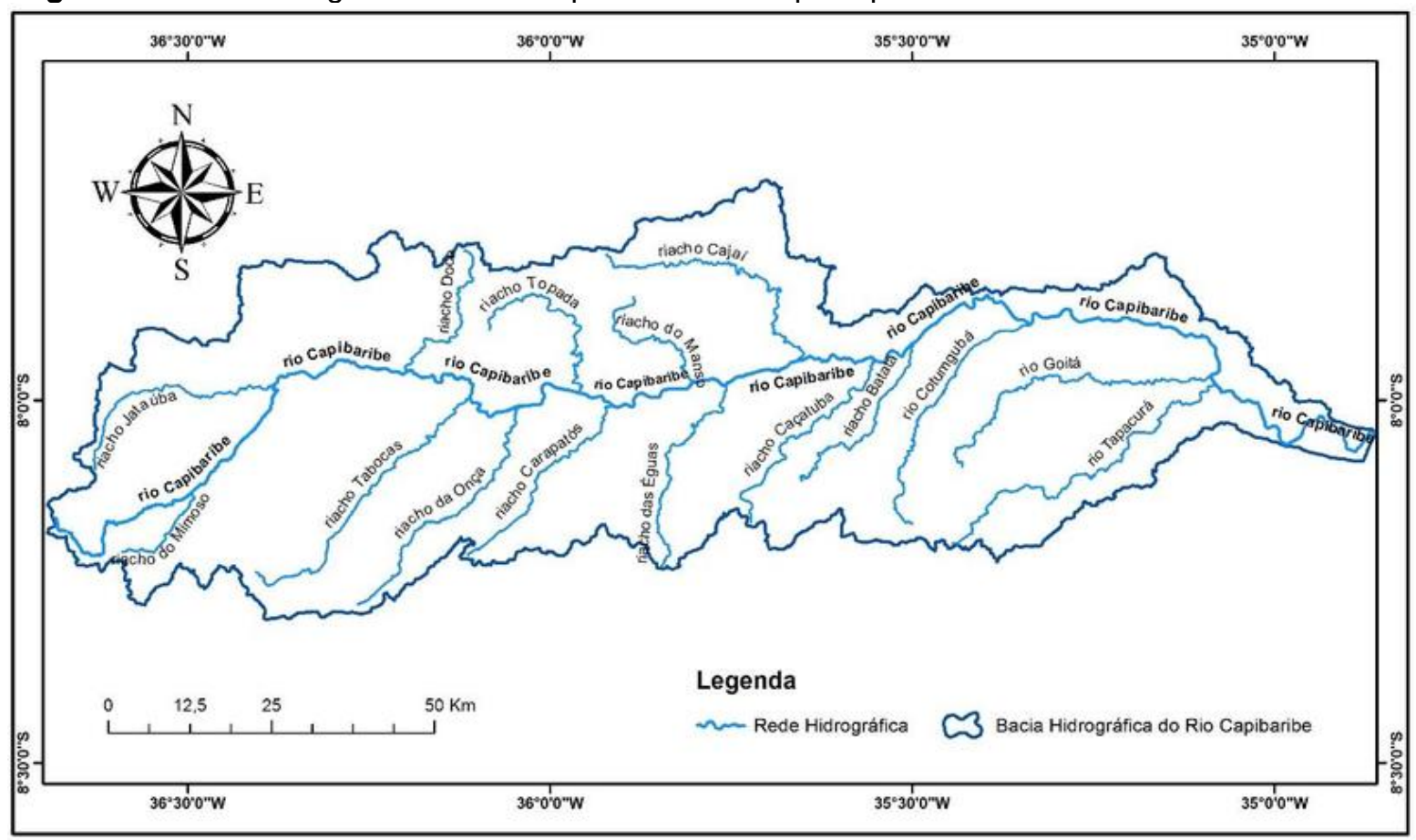

Fonte: Silva et. al. (2016) 
Apresenta um setor industrial bastante diversificado, com importante polo de confecções no alto Capibaribe demandando fornecimento adequado e com fortes impactos ambientais pelos efluentes dos processos de lavagem e destonagem de tecidos e uma cadeia produtiva sucroalcooleira, situada no terço médio abaixo da bacia, que gera elevados volumes de efluentes, tendo como consequência a contaminação de solos e mananciais hídricos (PERNAMBUCO, 2010a).

As atividades industriais mais comuns na BHRC são associadas a produtos alimentares, minerais não metálicos, têxtil, metalúrgicas, químicas, farmacêuticas e veterinárias, indústria sucroalcooleira, couros, matéria plástica, perfumes, sabões, velas, bebidas, mecânica, material elétrico e de comunicação, material de transporte e madeira (PERNAMBUCO, 2010a).

O PHA Capibaribe foi resultado do contrato № 004/2009 firmado entre o Governo de Pernambuco, por meio da Secretaria de Recursos Hídricos e Energéticos (SRHE-PE), e o Consórcio Projetec - Projetos Técnicos Ltda e BRL Ingénierie, com recursos do PROAGUA Nacional/ Banco Mundial. Nele foram propostas diferentes ações com o objetivo de equacionar os problemas ambientais da bacia do Capibaribe (PERNAMBUCO, 2010b). Essas ações foram identificadas em três eixos temáticos:

Eixo I - Socioambiental - são as ações relacionadas à recomposição do equilíbrio do ambiente, atuando sobre a qualidade da cobertura vegetal, a proteção dos solos e ao resgate da importância do Rio Capibaribe no contexto da bacia e do Estado;

Eixo II - Infraestrutura Hídrica - dá ênfase em suas ações no saneamento ambiental voltado para a melhoria das condições de vida de famílias que ocupam áreas rurais difusas, com alternativas simplificadas para o abastecimento de água e saneamento. Compreende também ações de revitalização da calha do Rio Capibaribe que se somam aos esforços que vêm sendo empreendidos pelos gestores públicos municipal, estadual e federal;

Eixo III - Gestão dos Recursos Hídricos - reúne o conjunto de ações voltadas para o aperfeiçoamento do Sistema Estadual de Recursos Hídricos, disponibilizando ferramentas para a gestão e controle dos recursos hídricos da bacia. Abrange ainda a pesquisa e o monitoramento de pequenas bacias em zonas hidrologicamente homogêneas em diferentes regiões fisiográficas, para o desenvolvimento de modelos hidrológicos adequados às condições ambientais da bacia do Rio Capibaribe. 


\section{METODOLOGIA}

A metodologia utilizada para analisar o progresso das ações do PHA Capibaribe relativo ao eixo de Gestão dos Recursos Hídricos ocorreu a partir das seguintes etapas principais: análise da documentação disponível para a comunidade, reuniões para obter informações mais restritas a atuação do $\mathrm{COBH}$ com membros do mesmo e funcionários de órgãos públicos, elaboração de gráficos e análise crítica do planejamento do plano hidroambiental e as ações realizadas.

Primeiramente, a análise documental verificou o PHA Capibaribe com o intuito de identificar os órgãos responsáveis pelos eixos do plano da bacia e as ações planejadas. Então, uma planilha foi estruturada em Excel levando em consideração as ações planejadas e o status de realização, onde se classificou a situação em: não informada, não iniciada, iniciada e concluída.

Destaca-se que apesar do documento com planejamento de diversas ações disponibilizadas para a comunidade serem públicos, a dificuldade principal consiste em identificar o que de fato já foi feito, por isso a importância de entrar em contato com as instituições responsáveis.

A partir da identificação dos responsáveis pelas ações, houve cinco reuniões diretamente com funcionários de órgãos públicos e membros do $\mathrm{COBH}$ Capibaribe, separadamente, para ter acesso as informações e documentos restritos como as atas de reuniões do comitê e da Câmara Técnica.

Paralelamente, realizou-se a consulta online a informações disponibilizadas nos sites oficiais dos órgãos públicos que tinham relação com PHA Capibaribe, identificados anteriormente: Agência Nacional de Águas (ANA), Agência Pernambucana de Águas e Clima (APAC), Secretaria de Recursos Hídricos e Energéticos (SRHE-PE) e Agência Estadual de Meio Ambiente (CPRH).

Posteriormente, com o preenchimento da planilha foram gerados gráficos para apresentação das informações coletadas de forma resumida, permitindo assim a análise quantitativa do planejamento e da execução do eixo III da gestão de recursos hídricos do PHA Capibaribe. Além disso, realizou-se uma análise crítica considerando todo o processo.

A Figura 3 apresenta um fluxograma para resumir a estruturação das etapas da metodologia do presente artigo. 
Figura 3 - Fluxograma resumo da metodologia realizada



Fonte: Autores (2020)

\section{RESULTADOS E DISCUSSÃO}

Existem três ações consideradas prioritárias no PHA Capibaribe: fortalecimento do comitê da bacia do Capibaribe; programa de apoio aos municípios da bacia do Rio Capibaribe para gestão hidroambiental; e o plano de monitoramento hidroambiental do Rio Capibaribe. Nota-se que essas três ações estão no grupo das iniciadas e/ou concluídas. Além disso, percebe-se que a partir do status do andamento das ações planejadas, $23 \%$ não foram iniciadas, $31 \%$ foi iniciado, $23 \%$ foi concluída e $23 \%$ as intuições responsáveis não souberam informar, como é possível observar na Figura 4.

Figura 4 - Andamento dos planos PHA Capibaribe

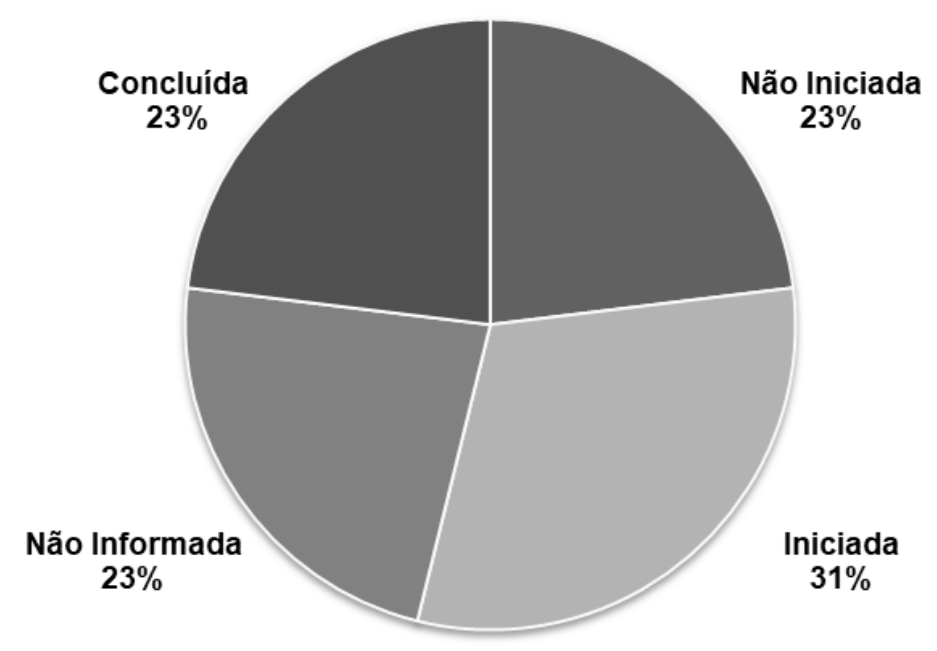

Fonte: Autores (2020)

A Tabela 1 apresenta os órgãos responsáveis, valor estimado e o andamento da cada uma dessa ação. Nota-se que dentre as três ações que são consideradas prioritárias (fortalecimento do comitê da bacia do Capibaribe; programa de apoio aos municípios da 
bacia do Rio Capibaribe para gestão hidroambiental; e o plano de monitoramento hidroambiental do Rio Capibaribe) estão no grupo das iniciadas e/ou concluídas.

Tabela 1 - Resumo das ações propostas pelo PHA Capibaribe no eixo gestão dos recursos hídricos

\begin{tabular}{|c|c|c|c|}
\hline Ação do Plano de Investimentos & $\begin{array}{l}\text { Tempo de } \\
\text { implantação }\end{array}$ & Valor estimado & $\begin{array}{l}\text { Status da } \\
\text { ação }\end{array}$ \\
\hline $\begin{array}{l}\text { Implementação de "bacias representativas" nas } \\
\text { diferentes zonas fisiográficas da bacia do Rio } \\
\text { Capibaribe }\end{array}$ & 36 meses & $\mathrm{R} \$ 952.321,35$ & $\begin{array}{l}\text { Não } \\
\text { iniciada }\end{array}$ \\
\hline $\begin{array}{l}\text { Implementação de sistema de monitoramento em } \\
\text { tempo real em áreas inundáveis na bacia do Rio } \\
\text { Capibaribe }\end{array}$ & 18 meses & $\mathrm{R} \$ 1.407 .870,44$ & Concluída \\
\hline $\begin{array}{l}\text { Plano de contingência para inundações na bacia } \\
\text { do Rio Capibaribe }\end{array}$ & 12 meses & $\mathrm{R} \$ 835.210,66$ & Concluída \\
\hline Plano de monitoramento hidroambiental & 18 meses & $\mathrm{R} \$ 1.271 .656,87$ & Concluída \\
\hline $\begin{array}{l}\text { Elaboração de cadastro de usuários de recursos } \\
\text { hídricos na bacia do Rio Capibaribe e } \\
\text { sistematização em banco de dados }\end{array}$ & 12 meses & $\mathrm{R} \$ 965.128,67$ & Iniciada \\
\hline $\begin{array}{l}\text { Estudos para cobrança pelo uso dos recursos } \\
\text { hídricos na bacia do Rio Capibaribe }\end{array}$ & 18 meses & $\mathrm{R} \$ 1.044 .949,63$ & Iniciada \\
\hline $\begin{array}{l}\text { Implementação da proposta de referência para } \\
\text { enquadramento dos corpos hídricos para a bacia } \\
\text { do Rio Capibaribe }\end{array}$ & 12 meses & $\mathrm{R} \$ 839.503,38$ & Iniciada \\
\hline $\begin{array}{l}\text { Sistema informatizado de acompanhamento e } \\
\text { controle de outorgas na bacia do Rio Capibaribe }\end{array}$ & 12 meses & $\mathrm{R} \$ 980.630,21$ & $\begin{array}{l}\text { Não } \\
\text { iniciada }\end{array}$ \\
\hline $\begin{array}{l}\text { Programas de uso racional das águas em } \\
\text { indústrias formais e informais na bacia do Rio } \\
\text { Capibaribe }\end{array}$ & 12 meses & $\mathrm{R} \$ 742.391,48$ & $\begin{array}{c}\text { Não } \\
\text { informado }\end{array}$ \\
\hline $\begin{array}{l}\text { Fortalecimento do Comitê da bacia do Rio } \\
\text { Capibaribe }\end{array}$ & 36 meses & $\mathrm{R} \$ 824.438,09$ & Iniciada \\
\hline $\begin{array}{l}\text { Monitoramento do Impacto dos investimentos em } \\
\text { saneamento básico, sobre os reservatórios de } \\
\text { Jucazinho, Tapacurá e Carpina }\end{array}$ & 12 meses & $\mathrm{R} \$ 721.192,18$ & $\begin{array}{l}\text { Não } \\
\text { informado }\end{array}$ \\
\hline $\begin{array}{l}\text { Programa de apoio aos municípios da bacia do } \\
\text { Rio Capibaribe para a gestão hidroambiental }\end{array}$ & 36 meses & $\mathrm{R} \$ 2.040 .749,95$ & Iniciada \\
\hline $\begin{array}{l}\text { Reuso de esgoto doméstico tratado no } \\
\text { aproveitamento hidroagrícola na bacia do Rio } \\
\text { Capibaribe }\end{array}$ & $\begin{array}{c}\text { De acordo com a } \\
\text { disponibilidade de } \\
\text { área e de solos no } \\
\text { município. }\end{array}$ & $\mathrm{R} \$ 5.126 .223,20$ & $\begin{array}{l}\text { Não } \\
\text { informado }\end{array}$ \\
\hline
\end{tabular}

Fonte: Autores (2020)

\subsection{Implementação de "bacias representativas" nas diferentes zonas fisiográficas da bacia do Rio Capibaribe}

As bacias representativas são utilizadas para extrapolar o conhecimento obtido nela para zonas homogêneas, sendo instrumentadas com aparelhos para o monitoramento e 
registro dos eventos hidrológicos e climáticos. O PHA Capibaribe propôs implementar duas bacias representativas e dar início à operação das redes de monitoramento.

Para tal, foi previsto 10 pluviômetros convencionais, 1 pluviógrafo, 1 estação climatológica completa, 2 estações fluviométricas com linígrafo e medição de descarga líquida e sólida, e parâmetros de qualidade da água. Contudo, nenhuma ação foi iniciada.

\subsection{Implementação de sistema de monitoramento em tempo real em áreas inundáveis na bacia do Rio Capibaribe}

Apesar das estruturas de barramento hídrico existentes, ainda existe o risco da calha do rio extravasar provocando inundações. Com o objetivo de minimizar esses riscos e implantar um sistema de alerta em tempo real eficiente visando fornecer subsídios à defesa civil e demais entidades envolvidas na gestão de recursos hídricos, o PHA Capibaribe propôs a implementação de um sistema de monitoramento em tempo real em áreas inundáveis.

Atualmente, há cinco plataformas de coleta de dados (PCD's), que monitoram em tempo real o nível dos rios Capibaribe e Tapacurá nas seguintes cidades: Limoeiro, São Lourenço da Mata, Toritama, Vitória de Santo Antão e Paudalho.

\subsection{Plano de contingência para inundações na bacia do Rio Capibaribe}

O Plano de Contingência é um conjunto de procedimentos e ações para atender a eventos desastrosos ou períodos de ameaças. Esse plano, no PHA Capibaribe, tem como objetivos a elaboração do diagnóstico das consequências socioeconômicas das inundações; elaboração do plano de contingência de inundações, desenvolvendo um modelo a ser seguido para a elaboração anual desses planos pelo Estado e municípios, além de fortalecer institucionalmente o sistema estadual e municipal de Defesa Civil.

Para cumprir essa ação foi inaugurada em 10 de junho de 2011 a Sala de Situação que fica localizada na APAC, mas sendo de responsabilidade da Coordenadoria de Defesa Civil de Pernambuco (CODECIPE) e das Defesas Civis Municipais. Seus principais objetivos são o de monitorar e emitir boletins das condições hidrometeorológicas, produzindo informações necessárias para o planejamento e a promoção de ações contra desastres naturais. Dessa forma, busca-se uma otimização e agilidade diante de eventos críticos. 


\subsection{Plano de monitoramento hidroambiental do Rio Capibaribe}

Este plano propõe reestruturar e otimizar o sistema de monitoramento da qualidade das águas superficiais e estruturar sistema de monitoramento das águas subterrâneas na bacia do Rio Capibaribe, controlando as fontes de poluição.

Atualmente, a APAC opera uma rede de monitoramento de qualidade de água, em 54 reservatórios em todo o Estado de Pernambuco, sendo 10 deles localizados na Bacia do Capibaribe (Poço Fundo, Oitis, Machado, Tabocas, Jucazinho, Carpina, Cursaí, Goitá, Tapacurá e Várzea do Una). Possui também um Sistema de Monitoramento de Poços na RMR, disponibilizado no site oficial da APAC com acesso público, onde é realizado o monitoramento em tempo real da vazão retirada de 276 poços. Essas informações alimentam o banco do QUALIAGUA, que tem caráter nacional.

\subsection{Elaboração de cadastro de usuários de recursos hídricos na bacia do Rio Capibaribe e sistematização em banco de dados}

O objetivo desta ação é elaborar o cadastro de usuários de recursos hídricos existentes na bacia hidrográfica, a fim de disponibilizar as informações no banco de dados do Cadastro Nacional de Usuários de Recursos Hídricos - CNARH. Essa identificação ajuda a alocação adequada dos recursos hídricos evitando futuros conflitos, como também serve de base para regularização dos usuários através do instrumento da outorga.

O plano está em andamento e tem como meta a realização do cadastro dos 1000 maiores consumidores da bacia. Entretanto, não foi possível obter informações sobre a quantidade de usuários já cadastrados.

\subsection{Estudos para cobrança pelo uso dos recursos hídricos na bacia do Rio Capibaribe}

A cobrança pelo uso dos recursos hídricos visa dar ao usuário uma indicação de seu real valor e incentivar a racionalização do seu uso, bem como obter recursos financeiros para o financiamento dos programas e intervenções contemplados nos planos de recursos hídricos. A viabilidade técnica e econômica da cobrança permitirá o aporte de recursos para implementação do plano de investimentos aprovado para a bacia hidrográfica. 
A ação proposta teve como objetivo principal subsidiar a implementação da cobrança pelo uso da água na bacia hidrográfica do Rio Capibaribe em águas de domínio do Estado de Pernambuco. Atualmente o plano está em andamento com contrato em todo o estado.

\subsection{Implementação da proposta de referência para enquadramento dos corpos hídricos para a bacia do Rio Capibaribe}

A proposta de enquadramento de referência visa atender, de forma satisfatória, aos usos atuais dos recursos hídricos na bacia hidrográfica. Tem como objetivos a aprovação de proposta de enquadramento dos corpos hídricos pelo Comitê da bacia e a definição das etapas para implementação do enquadramento.

Atualmente essa ação foi iniciada na bacia do Rio Ipojuca e o COBH Capibaribe espera que ela possa servir como parâmetro para implementação no Capibaribe. Uma outra ação que foi iniciada no âmbito do Projeto de Saneamento Ambiental (PSA) Ipojuca (COMPESA/APAC) consiste na contratação de consultoria para a elaboração de uma metodologia e sistema de monitoramento das ações e investimentos previstos no PHA Ipojuca. Tal metodologia poderá também ser adaptada e aplicada para monitoramento do PHA Capibaribe, ou ao menos servirá como base para futura implementação nesta bacia.

\subsection{Sistema informatizado de acompanhamento e controle de outorgas na bacia do Rio Capibaribe}

Há uma crescente demanda por outorgas do uso de água na bacia, o que faz com que seja cada vez mais indispensável o controle de qualidade dos rios e a garantia de manutenção do seu enquadramento e um controle mais eficiente sobre os efluentes lançados. Assim, é fundamental à implantação de um sistema que permita a manipulação ágil e adequada das informações sobre os usuários outorgados e os dados, bem como associá-los a critérios de decisão e emissão automática de relatórios.

Essa ação proposta teve como objetivos principais o desenvolvimento e implementação de sistema para consulta aos processos de outorga de uso da água e lançamento de efluentes, e a disponibilização das informações relativas às outorgas emitidas via web.

Atualmente, não se tem iniciado ainda esse plano para BHRC, apesar disso, a ANA possui o Sistema Federal de Regulação de Uso (REGLA), uma plataforma de solicitação e 
consulta de outorga nacional, onde também é possível verificar algumas outorgas no Rio Capibaribe cujo domínio é da União.

\subsection{Programas de uso racional das águas em indústrias formais e informais na bacia do Rio Capibaribe}

Essa ação proposta teve como objetivos a redução no consumo de água potável entre os usuários, ampliação do emprego de técnicas de reuso da água na bacia, redução de lançamento de efluentes industriais nos corpos hídricos, ações essas que são agravadas pelo crescimento demográfico e econômico.

Através da análise documental das Atas de reuniões do COBH Capibaribe e da Câmara Técnica, não foi possível obter informações a respeito do andamento desta ação. Entretanto, nota-se que há atividades pontuais de iniciativa privada, que não fazem parte do PHA Capibaribe, que cumprem tal objetivo. Entre elas, é possível citar o aproveitamento da água em indústria de lavanderia, em Toritama, que utiliza a técnica de reaproveitamento da água na lavagem do jeans. Com essa técnica é possível chegar a uma redução de $60 \%$ do consumo de água (SEBRAE, 2009).

\subsection{Fortalecimento do Comitê da bacia do Rio Capibaribe}

Os comitês de bacia hidrográfica desempenham um papel essencial na gestão de recursos hídricos, tais como: participar da elaboração, acompanhar a execução e aprovar o plano de recursos hídricos da bacia; aprovar o enquadramento dos corpos hídricos; propor critérios de isenção de outorga de direito de uso da água; propor os valores a serem cobrados pelos usos dos recursos hídricos; efetuar, mediante delegação e por intermédio da agência de bacia, a cobrança pelo uso da água.

A ação proposta tem como objetivo fortalecer o $\mathrm{COBH}$ para cumprimento de suas atribuições, proporcionando-Ihe suporte para o monitoramento, retroalimentação e acompanhamento do plano hidroambiental, nos limites de sua competência, além do acompanhamento da execução dos Planos de Investimentos. Na Tabela 2 é possível encontrar o andamento das metas propostas nessa ação. 
Tabela 2 - Metas com suas respectivas situações atuais

\begin{tabular}{|c|c|}
\hline Metas & Progresso \\
\hline $\begin{array}{l}\text { Estruturação da Secretaria do } \\
\text { COBH. }\end{array}$ & $\begin{array}{l}\text { Estrutura da secretaria está sendo viabilizada. Já foi } \\
\text { cedido equipamento de informática e móveis para a } \\
\text { estruturação da secretaria. }\end{array}$ \\
\hline $\begin{array}{l}\text { Garantir funcionamento das } \\
\text { plenárias, Câmaras Técnica } \\
\text { (CTs) e Grupos de Trabalho } \\
\text { (GTs). }\end{array}$ & $\begin{array}{l}\text { Plenária do } \mathrm{COBH} \text { vem se reunindo com } \\
\text { regularidade, sendo apoiada pela Gerência de Apoio } \\
\text { aos Organismos de Bacias (GAOB). O CT PHA foi } \\
\text { criada e vem se reunindo e os GTs serão } \\
\text { rearticulados e apoiados. }\end{array}$ \\
\hline $\begin{array}{l}\text { Organizar três fóruns } \\
\text { hidroambientais. }\end{array}$ & Fóruns não foram realizados. \\
\hline $\begin{array}{l}\text { Capacitar lideranças para a } \\
\text { gestão hidroambiental. }\end{array}$ & $\begin{array}{l}\text { Desde a implantação do COBH foram realizadas } \\
\text { algumas capacitações. }\end{array}$ \\
\hline $\begin{array}{l}\text { Viabilizar plano de comunicação } \\
\text { do COBH. }\end{array}$ & Plano de comunicação não foi executado. \\
\hline $\begin{array}{l}\text { Possibilitar integração com } \\
\text { conselhos de usuários da bacia. }\end{array}$ & $\begin{array}{l}\text { Não há conselhos de usuários nos reservatórios da } \\
\text { bacia do Capibaribe. }\end{array}$ \\
\hline $\begin{array}{l}\text { Estabelecer sistemática de } \\
\text { acompanhamento do PHA. }\end{array}$ & $\begin{array}{l}\text { Sistemática de acompanhamento do PHA vem } \\
\text { sendo estabelecida entre a CT PHA e a APAC. }\end{array}$ \\
\hline
\end{tabular}

Fonte: Os autores (2020)

\subsection{Monitoramento do Impacto dos investimentos em saneamento básico, sobre os reservatórios de Jucazinho, Tapacurá e Carpina}

As emissões de poluentes nos corpos d'água são causadoras de diversos problemas nos ecossistemas aquáticos, os quais tendem a se agravar como resultado do uso incorreto que o homem faz e das atividades que desenvolve na bacia hidrográfica. As consequências negativas da poluição da água podem ser de caráter sanitário, ecológico, social ou econômico. Além disso, o crescimento demográfico aliado ao crescimento econômico diversificou os usos dos recursos hídricos, produzindo inúmeras pressões sobre o ciclo hidrológico e sobre as reservas de águas superficiais e subterrâneas.

A ação proposta teve como objetivo principal estudar o impacto dos investimentos em saneamento básico nas cidades de Toritama, Limoeiro, Paudalho, Salgadinho e Vitória de Santo Antão sobre os reservatórios de Jucazinho, Tapacurá e Carpina. Através da análise documental das Atas de reuniões do COBH Capibaribe e da Câmara Técnica, não foi possível obter informações a respeito do andamento desta ação. 


\subsection{Programa de apoio aos municípios da bacia do Rio Capibaribe para a gestão hidroambiental}

A ação proposta teve como objetivo promover a desconcentração e a descentralização das instâncias e instrumentos da gestão ambiental e territorial no âmbito da Bacia Hidrográfica; atualizar o arcabouço legal municipal referente à questão hidroambiental; apoiar e criar condições necessárias para a implementação, fortalecimento e desenvolvimento institucional dos sistemas municipais de meio ambiente; apoiar a implementação e o desenvolvimento dos instrumentos de gestão ambiental e territorial no âmbito dos municípios inseridos na área da bacia hidrográfica e estimular a criação da rede estadual de $\mathrm{COBHs}$ e Conselhos de Meio Ambiente. Atualmente, o plano foi iniciado com ações que contribuem como os Planos Urbano Ambiental (PUAs).

\subsection{Reuso de esgoto doméstico tratado no aproveitamento hidro agrícola na bacia do Rio Capibaribe}

Os sistemas de reuso de esgoto doméstico tratado para fins de aproveitamento hidro agrícola estão diretamente relacionados com a preservação do meio ambiente através da prática de uso de água de qualidade inferior na agricultura, desta maneira, aumenta a disponibilidade hídrica da bacia aliviando a pressão sobre os recursos hídricos e preservando a qualidade da água dos corpos receptores. Entretanto, ressalva-se que a implantação do reuso de efluentes deve ser estudado e analisado de acordo com o tipo de atividade e cultura para atender os padrões mínimos da qualidade água para outro fim.

A ação proposta teve como objetivo implementar unidades piloto de reuso de esgoto doméstico tratado para aproveitamento agrícola através de técnicas de irrigação em povoados e comunidades com população acima de 100 famílias em áreas dos municípios da bacia hidrográfica do Rio Capibaribe. Porém, essa questão ainda precisa ser melhor estudada e debatida para evitar a contaminação de determinadas culturas, não sendo possível a utilização segura para qualquer plantação. Através da análise documental das Atas de reuniões do COBH Capibaribe e da Câmara Técnica, não foi possível obter informações a respeito do andamento desta ação. 


\subsection{Análise crítica da implantação da gestão a partir do PHA Capibaribe}

Diante do exposto fica evidente o não cumprimento do plano previsto no horizonte proposto pelo PHA Capibaribe. Outro aspecto negativo encontrado durante esta análise foi a dificuldade em coletar as informações a respeito do andamento do plano, onde cerca de um terço dele não se obteve informações. Além disso, não foi possível identificar se todas as ações iniciadas foram concluídas pois os órgãos não tinham esse controle detalhado. Por se tratar de ações relativas à gestão, as ações iniciadas e concluídas estão em constantes mudanças sempre sendo adaptadas e melhoradas.

Observou-se o surgimento natural do uso racional das águas em indústrias formais e informais, de algumas ações sem a necessidade da abordagem no plano da bacia, ou seja, interesses privados buscaram alternativas de economizar água através do reuso, independentemente de exigências por órgãos públicos.

O plano hidroambiental em uma bacia hidrográfica mostrou-se fundamental, pois sem ele as ações apareceriam de forma desorganizada sem nenhuma integração uma com as outras. Além disso, outro aspecto que corrobora com a utilidade do PHA Capibaribe é que ele serviu com uma "atualização" do Plano Estadual de Recursos Hídricos, visto que este está completamente desatualizado sendo de 1998 no Estado de Pernambuco.

Um ponto que chama atenção no PHA Capibaribe foi a delegação das ações a diferentes atores o que é bastante positivo, mas a não comunicação entre eles e o questionamento acerca da sua viabilidade de assumir tal ação causaram o não andamento da mesma, sendo esse um dos principais motivos para o não cumprimento do plano previsto no horizonte proposto.

Além disso, a dificuldade financeira também foi responsável pelo não andamento correto do plano, como exemplo, o Fundo Estadual de Recursos Hídricos (FEHIDRO) que é uma fonte mantedora de diversas ações, atualmente foi cortado. Também, a própria ineficiência da gestão pública contribui para a ineficiência das atividades.

\section{CONCLUSÕES}

As ações planejadas no PHA Capibaribe relacionadas à gestão foram bem descritas no documento, entretanto a implantação prática encontrou diversas dificuldades. Dessa forma, a partir do status do andamento dessas ações, aproximadamente um quarto das ações foram de fato iniciadas e concluídas. 
Notou-se que um dos maiores desafios na implantação da gestão foi definir os responsáveis por cada atividade, o acompanhamento das ações e a integração entre diferentes instituições públicas. Dessa forma, cercar de um quarto das ações, os órgãos públicos não conseguiam identificar em qual status estava a implementação.

Portanto, percebe-se que a elaboração de um documento para gestão dos recursos hídricos em uma bacia hidrográfica, não garante que essas ações serão cumpridas nos prazos estabelecidos. Além disso, no plano da bacia é primordial identificar e informar os responsáveis por cada uma das ações estabelecidas e criar uma plataforma integradas para que diferentes instituições possam informar o andamento das ações.

\section{REFERÊNCIAS}

ANDRADE, M. C. O. Pernambuco e o trópico. Revista do IEB, São Paulo, n. 45 p. 11-20, 2007. https://doi.org/10.11606/issn.2316-901X.v0i45p11-20

BARBOSA, F. D.; LOPES, M. C.; CARPI JUNIOR, S. Análise de alguns instrumentos de participação social na gestão dos recursos hídricos. Periódico Eletrônico Fórum Ambiental da Alta Paulista, v. 11, n. 6, p. 44-58, 2015. https://doi.org/10.17271/1980082711620151235

BRASIL. Lei no 9.433/97, de 8 de janeiro de 1997. Disponível em: http://www.planalto.gov.br/ccivil 03/LEIS/L9433.htm. Acesso em: 20 abr. 2020.

COSTA, M. S.; LIMA, K. C.; ANDRADE, M. M.; GONÇALVES, W. A. Tendências observadas em extremos de precipitação sobre a região Semiárida do Nordeste do Brasil. Revista Brasileira de Geografia Física, v. 8, n. 5 p. 1321-1334, 2015. https://doi.org/10.5935/1984-2295.20150071

DULAC, V.; CRUZ, R. Mapeamento das Ações de Gestão dos Recursos Hídricos no Âmbito de um Comitê de Gerenciamento de Bacia Hidrográfica. Revista Brasileira de Recursos

Hídricos, [s.I.], v. 20, n. 3, p.583-593, 2015. https://doi.org/10.21168/rbrh.v20n3.p583-593

FIGUEIREDO, A. A. O. Redução de perdas na rede de abastecimento de água em cidades do semiárido no Agreste de Pernambuco. 2019. Dissertação (Mestrado) - Universidade de Pernambuco, Recife, 2019.

GOUVEIA, R. L.; PEDROSA, I. V. Gestão das políticas governamentais para os recursos hídricos, Recife, Pernambuco, Brasil. Desenvolvimento em Questão, n. 32, p. 103-126, 2015. https://doi.org/10.21527/2237-6453.2015.32.103-126

JACOBI, P. R.; BARBI, F. Democracia e participação na gestão dos recursos hídricos no Brasil. Rev. Katál, Florianópolis, v. 10, n. 2, p. 237-244, 2007. https://doi.org/10.1590/S1414$\underline{49802007000200012}$

JACOBI, P. R. Aprendizagem social, desenvolvimento de plataformas de múltiplos atores e governança da água no Brasil. Revista INTERthesis, Florianópolis, v.7, n.1, pp. 69-95, jan./jul. 2010. https://doi.org/10.5007/1807-1384.2010v7n1p69 
LIMA, M. C. G.; SÁ, S. M. F.; SOUZA, W. M.; SANTOS, T. E. M. Impactos gerados e a gestão da bacia do Rio Capibaribe-PE. Journal of Environmental Analysis and Progress, v. 3, n. 1, p. 7585, 2018. https://doi.org/10.24221/jeap.3.1.2018.1658.075-085

LÖBLER, Y.G.F.; SILVA, R.S.G.; DUTRA, M.T.D.; BARBOSA, I.M.B.R.; MONTENEGRO, S.M.G.L. Aplicação de indicador de gestão de recursos hídricos na bacia hidrográfica do Rio Capibaribe. In: Congresso Brasileiro de Gestão Ambiental, 2016. [Anais...] Campina Grande, PB, 2016.

MESQUITA, L. F. G. Gestão de recursos hídricos na bacia hidrográfica do rio Preto: atores, ações e conflitos. 2017. 182 f. Dissertação (Mestrado) - Universidade de Brasília, Brasília, DF, Brasil.

PERNAMBUCO. Secretaria de Recursos Hídricos. Plano Hidroambiental da Bacia Hidrográfica do Rio Capibaribe (Tomo I - diagnóstico hidroambiental - Volume 01/03). Recife, 2010a, 389p.

PERNAMBUCO. Secretaria de Recursos Hídricos. Plano Hidroambiental da Bacia Hidrográfica do Rio Capibaribe (Tomo III - Planos de Investimentos - Volume 03/03). Recife, 2010b, 286 p.

RHODEN, A. C.; FELDMANN, N. A.; MUHL, F. R.; RITTER, A. F. S.; MOREIRA, A. A importância da água e da gestão dos recursos hídricos. Revista ciências agroveterinárias e alimentos, Porto Alegre, n. 1, p. 1-17, 2016.

RIBEIRO NETO, A.; SCOTT, C. A. ; LIMA, E. A. ; MONTENEGRO, S. M. G. L. ; CIRILO, J. A. Infrastructure sufficiency in meeting water demand under climate-induced socio-hydrological transition in the urbanizing Capibaribe River basin - Brazil. Hydrology and Earth System Sciences, v. 18, p. 3449-3459, 2014. https://doi.org/10.5194/hess-18-3449-2014

SALGUEIRO, J. H. P. DE B. ; PINTO, E. J. A. ; MONTENEGRO, S. ; SILVA, B. B. ; SOUZA, W. M. Tendência de índices pluviométricos na bacia do Rio Capibaribe-PE e sua influência na gestão dos recursos hídricos. Revista Brasileira de Geografia Física, v. 7, n. 5, p. 1002-1014, 2014.

\section{SERVIÇO BRASILEIRO DE APOIO ÀS MICRO E PEQUENAS EMPRESAS}

(SEBRAE). Lavanderia pernambucana enfoca uso racional da água. 2009. Disponível em: http://www.df.agenciasebrae.com.br/sites/asn/uf/DF/lavanderia-pernambucana-enfoca-usoracional-da-agua,f81bb7a5feb26410VgnVCM1000003b74010aRCRD . Acesso em: 16 abr. 2020.

SILVA, R. N.; GOMES, D. D. M. ; LIMA, C. E. S. ; GOLDFARB, M. C. Uso do Índice RDE para Deteminação de Anomalias de Drenagem no Rio Capibaribe (PE). Revista Eletrônica em

Gestão, Educação e Tecnologia Ambiental, v. 20, p. 552-565, 2016.

https://doi.org/10.5902/2236117019951

SILVA, R. N.; GOMES, D. D. M.; LIMA, C. E. S.; GOLDFARB, M. C. Uso do índice RDE para determinação de anomalias de drenagem no Rio Capibaribe (PE). Revista Eletrônica em Gestão, Educação e Tecnologia Ambiental Santa Maria, v. 20, n. 1, p. 552-565, 2016. https://doi.org/10.5902/2236117019951

THEODORO, H. D.; NASCIMENTO, N. O.; HELLER, L. Descentralização institucional e gestão de recursos hídricos sob o enfoque legal: o caso do comitê da bacia hidrográfica do rio das Velhas, MG, Brasil. Brazilian Journal of Biosystems Engineering, v. 10, n. 3, p. 273-287, 2016. https://doi.org/10.18011/bioeng2016v10n3p273-287

TUNDISI, J. G. A governança da água. In: PAULA, João Antônio de. (Org.). Água. 2 ed. Belo Horizonte: Editora da UFMG, 2013, p. 222-235. 